\title{
Trimodal Therapy in Muscle Invasive Bladder Cancer Management
}

\author{
Elvira Polo-Alonso ${ }^{1}$, Cynthia Kuk ${ }^{2,3}$, Georgi Guruli ${ }^{4}$, Asit K. Paul ${ }^{5}$ \\ George Thalmann ${ }^{6}$, Ashish Kamat ${ }^{7}$, Eduardo Solsona ${ }^{1}$, George Thalmann ${ }^{8}$, Alfredo I. \\ Urdaneta $^{9}$ \\ Alexandre R Zlotta ${ }^{2,3}$, Maria C Mir ${ }^{1}$ \\ ${ }^{1}$ Department of Urology, Fundacion Instituto Valenciano de Oncologia, Valencia, \\ Spain \\ ${ }^{2}$ Division of Urology, Departments of Surgical Oncology, Princess Margaret Cancer \\ Centre, University Health Network, University of Toronto, Toronto, ON, Canada \\ ${ }^{3}$ Division of Urology, Department of Surgery, Sinai Health System, Mount Sinai \\ Hospital, Toronto, ON, Canada
}

${ }^{4}$ Division of Urology. VCU School of Medicine, Richmond, VA, USA

${ }^{5}$ Division of Hematology, Oncology and Palliative Care, Department of Internal Medicine, VCU Health, Richmond, Virginia

${ }^{6}$ Division of Hematology, Oncology and Palliative Care, Department of Internal Medicine, VCU Health, Richmond, Virginia

${ }^{7}$ Department of Urology, MD Anderson Cancer Center, Houston, TX, USA

${ }^{8}$ Department of Urology, University Hospital of Bern, Bern, Switzerland

${ }^{9}$ Division of Hematology, Oncology and Palliative Care, Department of Internal Medicine, VCU Health, Richmond, Virginia

Keywords: Bladder sparing. Chemoradiotherapy. Trimodal therapy. Muscle invasive bladder cancer.

Abstract: 245; Word Count: 4136; References: 56; Tables: 4; Figures:1

Abbreviations: TMT: Trimodal Therapy; MIBC: Muscle Invasive Bladder Cancer; RC: Radical Cystectomy; TURBT: Transurethral Resection Bladder Tumor; OS: Overall Survival; CSS: Cancer Specific Survival; CR: Complete 
Response; SC: Systemic Chemotherapy; 5-FU/MMC: 5-Fluoruracil/Mytomicin C; NMIBC: Non Muscle Invasive Bladder Cancer; BCG: Bacillus CalmetteGuerin; QoL: Quality of Life.

\section{Corresponding Author:}

M. Carmen Mir Maresma, MD, PhD, FEBU

Department of Urology

Fundacion Instituto Valenciano Oncologia

Valencia, Spain

e-mail: mirmare@yahoo.es 


\section{ABSTRACT}

\section{INTRODUCTION}

Radical cystectomy (RC) is the current mainstay for muscle-invasive bladder cancer (MIBC). Concerns regarding morbidity, mortality and quality of life have favoured the introduction of bladder sparing strategies. Tri-modal Therapy, combining transurethral resection, chemotherapy and radiotherapy is the current standard of care for bladder preservation strategies in selected patients with MIBC.

\section{EVIDENCE ACQUISITION}

A comprehensive search of the Medline and Embase databases was performed. A total of 19 studies were included in a systematic review of bladder sparing strategies in MIBC management was carried out following the Preferred Reporting Items for Systematic Reviews and Meta-Analysis (PRISMA).

\section{EVIDENCE SYNTHESIS}

The overall median complete response rate after TMT was 77\% (55-93). Salvage cystectomy rate with TMT was $17 \%$ on average (8-30). For TMT, the 5-year cancer-specific survival and overall survival rates range from $42-82 \%$ and $32 \%$ - 74\%, respectively. Currently data supporting neoadjuvant or adjuvant chemotherapy in bladder sparing approaches are emerging but robust definitive conclusions are still lacking. Gastrointestinal toxicity rates are low around 4\% 
(0.5-16), whereas genitourinary toxicity rates reached $8 \%$ (1-24). Quality of Life outcomes are still underreported.

\section{CONCLUSIONS}

Published data and clinical experience strongly support trimodal therapy as an acceptable bladder sparing strategy in terms of oncological outcomes and quality of life in selected patients with MIBC. A strong need exists for specialized centers, to increase awareness among urologists, to discuss these options with patients and to stress the increased participation of patients and their families in treatment path decision-making. 


\section{Introduction}

In Europe and in North America, bladder cancer (BC) is the fourth most frequent cause of cancer in men and the second most common genitourinary malignancy (1). Radical cystectomy (RC) with pelvic lymph node dissection and urinary diversion has been the standard treatment for muscle-invasive bladder cancer (MIBC) (2).

However, despite important improvements in surgical technique and perioperative management (such as robot assisted radical cystectomy with intracorporeal urinary diversion $(3,4)$ and enhance recovery after surgery (ERAS) protocols (5) ), RC is still associated with major complications and even perioperative mortality $(6,7)$. Although organ-sparing approaches in $\mathrm{BC}$ patients who often present with multifocal disease may not be indicated, a subset of patients presenting with unifocal disease may benefit. Bladder preservation has been suggested as an alternative to RC in selected patients with MIBC - the goal being to improve long-term quality of life, without compromising oncologic outcomes.

Several bladder sparing strategies have been described. These include monotherapies, such as: radiation alone (RT), chemotherapy alone and radical transurethral bladder resection (TURBT) and multimodal approaches (such as TURBT plus chemotherapy, in conjunction with radiotherapy, named trimodality (TMT)).

In general single modality therapy is not recommended, at least with a curative rather than palliative intent (2). Recent publications have suggested that 
TMT in selected MIBC patients provides similar oncological outcomes compared to RC (8). Previous systematic reviews have supported the rationale of TMT as the bladder preservation of choice in well-selected MIBC patients (9-11).

In the current review, we provide an overview of the available TMT strategies for MIBC focusing on oncological and functional outcomes.

\section{Evidence acquisition}

A comprehensive literature search in Medline and Embase was performed. The search included articles written in English reporting on bladder-sparing strategies in MIBC from 1990 to December 2019. A specific search strategy was designed combining the following keywords "bladder preservation", "bladder sparing", "chemoradiotherapy", "trimodality" and "muscle invasive bladder cancer" and Mesh Terms. In particular, the following search blocks were used for the MEDLINE database (((()bladder preservation) OR radical cystectomy) OR bladder sparing[MeSH Terms])) AND ((((((muscle invasive bladder cancer) OR bladder neoplasm) OR trimodal therapy) OR bladder cancer) OR bladder preservation) OR bladder neoplasm[MeSH Terms]).

As recommended in the Preferred Reporting Items for Systematic Reviews and Meta-Analysis (PRISMA), we used the population, intervention, comparator and outcomes (PICO) approach to define study eligibility. Studies were considered relevant if they included adult patients diagnosed with MIBC and not eligible for cystectomy and offered bladder sparing strategies (RT alone, TURBT alone, 
TURBT plus chemotherapy, TURBT plus chemo-RT). Outcomes studied included rate of complete response (CR), overall and cancer-specific survival (CR, OS, CSS) and rate of salvage cystectomy (SC).

Study types considered eligible were randomized control trials (RCTs) and, in the absence of available RCTs, comparative non-randomized prospective or retrospective studies. Case reports, editorials, letter, congress abstract and congress communications were not eligible. After exclusion of duplicates and articles unrelated to the topic of this review $(\mathrm{n}=\mathrm{XXX}), \mathrm{XX}$ records were screened by two independent reviewers (E.P.,MC.M.) using a dedicated screening form. Disagreement was solved by a third party (C.K.), who supervised the systematic review process. The full-text of XX articles was assessed for final eligibility. Finally, XX prospective studies fullfilling all PICOS criteria were included in the qualitative analysis. The selection of articles is shown in a PRISMA diagram (Figure 1).

Complete response (CR) after TMT has been defined in most series as "no visible tumour on cystoscopy, negative tumour site biopsy and negative urine cytology.”

\section{Evidence Synthesis}

The key characteristics of the studies included in the review are reported in Table 1. Overall, 10 prospective studies $(2$ phase III trials $(12,13)$ and 8 phase II trials (14-21)) and 9 retrospective single institution studies (22-30), published 
between 1993 and 2019, including 3642 patients undergoing TMT for MIBC, were selected for final qualitative analysis.

\subsection{Patient's Characteristics}

Among the included studies, the overall median patient age ranged between 62 and 71 years (Table 1).

Few studies provided information on patients' comorbidity burden and/or performance status at enrollment, highlighting heterogeneity of patient selection criteria. One of the phase III prospective trials reported a $60 \%$ of patients included with performance status 0 . All studies included patients with clinical diagnosis of MIBC (cT2-cT4), except 2 that also included HGT1 patients. In 7 studies patients were included with $\mathrm{cNx}$ staging.

\subsection{Oncologic Outcomes of patients undergoing TMT}

One of the cornerstones of TMT for MIBC is the large variability on patient selection and treatment strategies available. This makes oncological outcomes reporting equivocal in some cases.

The median follow-up in the prospective TMT trials included in our review ranged between 23 and 72 months; and between 27 and 94 months for prospective single series reports (Table 1). In eleven out of nineteen studies, the median follow-up was 5 years or longer.

9 studies reported utilization of cisplatin as a radiosensitizer; 3 utilized gemcitabine and 5-FU/MMC. A total of 6 studies did not specify the type of radiosensitizer included. Only 5 studies reported on the usage of neoadjuvant chemotherapy prior to TMT. 
The complete response (CR) rates ranged between 55\% and 93\% (median 70\%). A total of 7 studies reported CR rates above $80 \%$. Patients with cT2 disease had significantly higher rates of CR compared to cT3-T4a disease (83\% vs $63 \%, \mathrm{p}<0.001)$. In addition, patients who achieved CR after treatment had better OS rates compared to those who did not (23) (Table 1). The only prospective phase III trial reported CR rates of $60 \%$ (13). Thus, approximately $30 \%$ of patients who attempted to retain their bladders were not able to do so. 5year overall survival (OS) rates in published trials range from $48-65 \%$. In a recent pooled- analysis of the RTOG trials, Mak et al. reported a 5-year OS rate of $57 \%$ (62\% for cT2; $49 \%$ for cT3-4) (15). In this pooled analysis, at a median follow-up of 8 years, similar survival outcomes and response rates amongst older and younger patients were demonstrated. These findings support the use of this treatment approach in patients younger than 65 years old as well.

Reported CSS rates in published series are presented in Table 1 (12-30). Overall, 5-year CSS rates ranged from $42 \%$ to $82 \%$. Of note, 3 reports were based on 2-3 years outcomes.

In a pooled analysis of various RTOG trials (15) 5-year and 10-year CSS rates of $71 \%$ and $65 \%$, respectively have been reported. In another recent study, including the pooling of 8 different gemcitabine based protocols, 5-year CSS reached $80.9 \%$ (24).

The 5-year OS was 50\% in the current review, ranging from 32 to $74 \%$ (Table 1). Amongst the different authors and institutions, there is a clear heterogeneity in terms of length and intensity of follow-up, patient selection 
criteria and treatment protocols - all aspects that could explain the wide range observed in CSS and OS rates.

Salvage Cystectomy (SC) in TMT is reserved for those patients that do not respond to treatment (immediate cystectomy) or develop an invasive recurrence during follow-up (delayed cystectomy). Literature review also showed a wide range of SC rates, between $7 \%$ and $27 \%$ (Table 1), decreasing due to advancement in chemo-RT treatments and proper patient selection. The MGH group (23) reported a dramatic reduction of risk of SC at 5 years during their 20year follow-up (from $42 \%$ at the initial period to $16 \%$ in their last update).

MIBC recurrence after CR achievement in the TMT series ranged between $4 \%$ and as high as $57 \%$. Over $80 \%$ of recurrences develop within the first 5 years. This speaks to patients' selection criteria. Local recurrence rates within the bladder range between 10 and 43\%, and pelvic node recurrence between 5 and 46\%. Metastatic rates after CR varied between 4 and 39\% (Table 2). Of note, SC performed after $\mathrm{CR}$ in the $\mathrm{MGH}$ long-term series provided worst survival outcomes than early SC (23).

The proportion of patients developing metastatic disease within 5 years after CR ranged between $4 \%$ and $32 \%$. Pelvic node recurrences were observed in $5 \%$ to $12 \%$ of series.

NMIBC recurrences can also develop. The proportion of NMIBC recurrence in this review ranged between $5 \%$ and $29 \%$. Optimal management is not as clearly defined as it is for MIBC recurrence. Sanchez et al. from MGH (31) have recently retrospectively reviewed their outcomes in patients with 
NMIBC recurrences after CR to TMT; 342 patients in their cohort achieved CR; 85 patients $(25 \%)$ developed a NMIBC recurrence after a median follow-up of 9 years. Median time to recurrence was 1.8 years. A recent pooled analysis of different RTOG trials (15) reported on the incidence of NMIBC recurrences as well (31\% at 5 years and $36 \%$ at 10 years). For the MGH group, the most frequent type of recurrence was pTis in $41 \%$ of cases, followed by $35 \%$ pTa and $20 \%$ pT1. 8 patients $(9 \%)$ were managed with immediate SC, 39 (46\%) underwent a TURBT with intra-vesical BCG administration, 35 patients (41\%) TURBT alone, 2 (2\%) TURBT with chemotherapy instillation and nephroureterectomy in one patient. It has previously been shown that $(32,33)$ TURBT plus intra-vesical BCG instillation is the most popular management for NMIBC recurrences following TMT. However, in patients with baseline CIS, Sanchez et al. reported an increased risk of NMIBC recurrence. The 10-year CSS rate was slightly lower in patients with NMIBC recurrences $(78.4 \%$ and $72.1 \%$, respectively, $\mathrm{p}=0.002$ ). Conversely, 10 -year OS were not significantly different amongst groups (43.6\% and 54.1\%, respectively, $\mathrm{p}=0.66)$. Among 39 patients who received BCG, 25 patients $(64 \%)$ developed a recurrence. A 3-year recurrence-free and progression-free survival after induction BCG of 59\% and $63 \%$, respectively, was reported. $49 \%$ of patients developed some form of toxicity during BCG induction, the most frequent being non-infective cystitis. Zietman at al. (33), in a similar analysis, noted that CSS was not decreased by initial treatment (68\% if TURBT and bladder instillation vs. $69 \%$ in case of immediate SC). 
Weiss et al. (32) also reported similar 10 year OS rates in patients with and without NMIBC recurrences ( $72 \%$ vs $79 \%, \mathrm{p}=0.78)$, however a decrease in survival is observed when a NMIBC recurrence is developed (50\% vs $76 \%$ at 10 years, $\mathrm{p}<0.001)$. All data supports that management of NMIBC recurrences require treatment with TURBT and intra-vesical instillations, however risk of delayed cystectomy still remains.

\subsection{Toxicity and Quality of Life (QoL) Outcomes Associated with} TMT

TMT is not exempt of short and long-term toxicities. Table 3 summarizes long-term grade 3-4 toxicity rates after TMT. Gastrointestinal toxicity grade 3 ranged between 0.5 and $16 \%$ and similarly, for genitourinary toxicity grade 3 (124\%). Very few cystectomies were performed due to toxic side effects. Completion treatment rates average $80-90 \%$ depending on the series. Late grade 3-4 toxicity rates ranged from 3 to $8 \%$ of patients $(12,30)$.

The major potential benefit of bladder preservation has been improving QoL while preserving bladder functions. Unfortunately, very few authors have performed qualitative evaluation of QoL outcomes through validated questionnaires. A single institution study has evaluated long-term survivors after TMT (34) . 32 patients underwent urodynamic studies (75\% rated as within normal limits) and 48 completed the QoL questionnaires (20\% urinary incontinence, $15 \%$ urinary urgency, $22 \%$ bowel symptoms, $54 \%$ with reported erections for intercourse). Similarly, Herman et al. (35) in their prospective trial 
also confirmed good bladder functional outcomes after gemcitabine based trimodality. Mak et al. (36) compared QoL in survivors of MIBC between those who underwent RC (109 patients) and those who received a TMT bladder sparing approach (64 patients). A total of $6 \mathrm{QoL}$ validated instruments were used. At a median follow-up of 5.6 years, patients that received TMT had better overall general QoL (by 9.7 points), better physical, socio-emotional and cognitive functions, better bowel, sexual function and impaired body image. This data supports TMT as a good alternative to RC in selected patients.

A French prospective phase II trial reported on 53 patients receiving TMT. Patients were assessed for QoL (EORTC QLQ-C30) at baseline, 6, 12, 24 and 36 months. Within 8-year follow-up 67\% reported satisfactory bladder function (37).

Very recently the 5-year, patient-reported, health-related quality of life (HRQoL) outcomes of the BC2001 trial have been published (38). Functional Assessment of Cancer Therapy - Bladder (FACT-BL) questionnaires were completed at baseline, end of treatment and 6, 12, 24, 36, 48 and 60 months after radiotherapy. Primary endpoint was change from baseline in the bladder cancer subscale (BLCS) at 12 months. HRQoL dropped at the end of treatment (BLCS -5.06 [99\% confidence interval: -6.12 to $-4.00, \mathrm{p}<0.001$ ]; overall FACT-B TOTAL score $-8.22[-10.76$ to $-5.68, \mathrm{p}<0.01])$, improving to baseline after 6 months. As a result, the authors found no evidence of impairment in HRQoL from the addition of chemotherapy.

\subsection{Radiotherapy Regimens}


Two main schedules of RT have been reported in TMT protocols - split and continuous. The split course protocols were developed at the Massachusetts General Hospital (MGH) (23) and adopted in the Radiation Therapy Oncology Group (RTOG) trials (15) . Induction RT (40-45 Gy) is delivered with concurrent chemotherapy. Following, response is assessed by cystoscopy with tumour site biopsies. A consolidation chemo-RT (to full dose radiation of 64-66 Gy) is only given to patients with evidence of $\mathrm{CR}$. The continuous course protocols were mainly used in the University of Erlangen (30) and other European institutions. Continuous protocols consist of full dose RT (64-66 Gy) with concurrent chemotherapy after maximal TURBT. Endoscopic evaluation is performed once treatment is completed. Split protocols aim to reduce the risk of uncontrolled loco-regional disease and complications related to SC with the trade-off of decreasing the bladder preservation rates. A recent systematic review and metaanalysis did not find significant differences in 5-year OS rates between both protocols, although the continuous protocol might have some advantages regarding $\mathrm{CR}$ and lower SC rates (10). In Toronto, a very stringent protocol including cystoscopies every 3 months for the first 2 years but without systematic biopsies, resulted in very comparable results (8).

The optimal radiation technique and dose have not yet been standardized. Several studies have focused on accelerated fractionation (39), but radiation fractionation has not provided a benefit with twice-daily treatment compared to once-daily fractionation (23). In the RTOG 0712 (14), the two arms included fluorouracil plus cisplatin + RT twice daily vs. gemcitabine + RT once daily. 
Toxicity and efficacy in the gemcitabine and once daily radiation were more favourable than $5 \mathrm{FU}$-cisplatin, where up to $65 \%$ of patients experienced a grade 3 or 4 related toxicity event.

Another area of controversy is the radiation field. It has previously been reported that up to $25-30 \%$ of cT2-T4 N0 patients undergoing RC have positive lymph node metastasis (40). Moreover, in $12 \%$ of patients with locally advanced MIBC, common iliac lymph nodes could be affected (41). Among node positive patients, 20-30\% remain alive at 5-year follow-up. These results may support the inclusion of pelvic lymph nodes in the radiation field due to under-staging concerns. Tunio et al. (17) showed no difference in bladder preservation, CSS and OS rates between whole-pelvis radiation and bladder-only technique covering the bladder with $2 \mathrm{~cm}$ margins. Noteworthy, both groups received cisplatin as radio-sensitizer in this series. In addition, side effects were lower in the bladder-only protocol.

Similarly, James et al. in their BC2001 trial (12) did not include pelvic nodes in the radiation field which included bladder plus $1.5 \mathrm{~cm}$ margin, reporting a 5\% pelvic nodal recurrence rate. Contemporary radiation protocols for bladdersparing in MIBC include bladder external-beam RT (either once or twice a day) and limited pelvic lymph nodes to an initial dose of $40 \mathrm{~Gy}$, with whole bladder boost of $54 \mathrm{~Gy}$ and a further tumour boost of 64-65 Gy.

Some centers use lipiodol, an agent injected around the base of the tumour resected at TURBT, visible on CT scan, to optimize targeting and delivery of radiation therapy as the bladder is mobile, as well as to minimize side effects (8). 


\subsection{Concurrent radio-sensitizing chemotherapy}

There is a lack of phase III trials comparing radio-sensitizing agents in terms of safety and efficacy. Most published trials have included cisplatin based protocols either alone or in combination with 5-fluoruracil (5-FU) and mitomycin C (MMC) or paclitaxel (9). It is well reported in NAC trials before cystectomy (42) that up 50\% of candidates may be unsuitable for cisplatin regimen therapies. Age, comorbidities and hydronephrosis might be causes of impaired renal function in those patients. As a result, alternative radio-sensitizing agents have emerged. The combination of MMC plus 5-FU concurrent with RT has shown significant improvement of loco-regional disease control and lower rates of SC, without increasing the number of adverse events, compared to RT alone (12). Gemcitabine is a good alternative as a radio-sensitizer as shown in phase I/II trials $(18,24)$. In addition, RTOG 0712 trial (14), as previously mentioned, has demonstrated a CR rate of $78 \%$ for gemcitabine and once daily radiation with fewer toxicity than 5-FU plus cisplatin and radiation twice a day arm. The completion rates in these trials were $93 \%$ in the 5 -FU/cisplatin vs. $92 \%$ in the gemcitabine. Other concurrent chemotherapy regimen include paclitaxel alone or combined with trastuzumab, described in the RTOG 0524 trial (43), with CR rates around $70 \%$ in both arms at 1 year follow-up. Completion rates were similar.

\subsection{Neoadjuvant / adjuvant Chemotherapy with TMT}


It has been shown that the addition of NAC before RC increased OS by $5 \%$ compared to RC alone (44). However, its benefit prior to trimodality in bladder-sparing strategies is still controversial.

In 5 of the studies included in this review, patients received NAC.

In non-randomized studies, NAC followed by chemoradiation resulted in encouraging outcomes and tolerability in cisplatin-eligible patients. In 57 patients with excellent ECOG and stage II disease (65\%), stage III disease (25\%), and regional nodal metastases (11\%), 2-year disease-specific survival rates was $88 \%$ (95\% CI 78.5-98.1) (45).

A randomised trial compared standard TMT protocol with the inclusion of two cycles of NAC (13). No impact on OS, Metastasis Free Survival or CR rates was observed by adding NAC. Moreover, the trial was closed prematurely because of poor patient tolerance due to toxicity. A recent systematic review and meta-analysis by Fahmy et al. (46) reported similar results when NAC plus TMT was compared to TMT alone. No significant differences were found between both groups in $\mathrm{CR}(76.2 \%$ vs $73 \%, \mathrm{p}=0.33)$, 5-year CSS $(72.4 \%$ vs $62.2 \%$, $\mathrm{p}=0.13)$ and 5-year OS (53.8\% vs 50.4\%, p=0.078). Some authors have suggested a selection bias in favour of the TMT population (9).

Some trials have included adjuvant chemotherapy after TMT in their protocols. As expected, there seems to be lower tolerability and completion rates than with NAC (15). In addition, when adjuvant chemotherapy is used, grade 3-4 toxicity rates increased $(14,19)$. 
In 70 patients with cT2-4a MIBC randomly assigned to Fluorouracil plus cisplatin and radiation twice a day or Gemcitabine, adjuvant gemcitabine/cisplatin chemotherapy was administered. Although disease-free survival at 3 years was $80 \%$, concerning toxicity was reported. $64 \%$ patients in the Fluorouracil arm experienced treatment-related grade 3 and 4 toxicities during protocol treatment, whereas $55 \%$ in the Gemcitabine arm. No phase III trials have been published that report on survival outcomes after adjuvant chemotherapy as primary endpoint in the TMT population.

There is currently no clear established role for the use of NAC or adjuvant chemotherapy for improving survival or local control in TMT bladder-sparing approach - some authors advocate a rationale towards its usage in suspicious node positive patients'. Further studies are needed in this setting.

However there is a real push for NAC. Experts are advocating that optimal TMT should include NAC whenever possible and concurrent chemotherapy is not enough (47) . The Toronto group has reported on the potential benefit of this approach in their series (48).

\subsection{TMT vs. Radical Cystectomy}

Over the last decade, several retrospective series including TMT have suggested similar oncologic outcomes compared with $\mathrm{RC}$ in selected MIBC patients. Definitive comparisons are difficult because of the lack of randomized trials comparing both treatment approaches. The median age of patients undergoing $\mathrm{RC}$ is younger compared to those undergoing TMT (66 in our 
review). Direct comparisons are difficult and prone to biases as TMT studies include $\mathrm{cT}$ and $\mathrm{cN}$ instead of $\mathrm{pT} / \mathrm{pN}$. A well-recognized $15-30 \%$ upstaging at RC has been described (49).

The SPARE trial aimed to compare RC vs TMT post NAC. This multiinstitutional prospective, randomized trial included cT2-cT3 N0M0 patients with MIBC fit for either treatment option. The primary endpoint of the trial was to demonstrate the non-inferiority of the TMT in terms of OS. Due to slow recruitment (45 patients randomized within 30 months) and frequent protocol deviations after randomization, the trial was stopped (50).

Three meta-analyses have been published in the recent years including the TMT vs RC comparison. Prospective and retrospective studies are included. Over 13000 patients between 1990 and 2013 were included in the first one published in 2015 (51). The 5-year OS was 57\% for TMT and 52\% for RC $(\mathrm{p}=0.04)$, however, when patients receiving $\mathrm{RC}$ and chemotherapy (current SOC) were included, a 53\% 5y-OS was observed $(\mathrm{p}=0.38)$. Thus, the results were unable to provide support for any inferiority. In a more recent meta-analysis, Vashistha et al. (52) found no differences in 5- and 10-year OS, CSS and progression-free survival rates between TMT and RC. It included patients until 2016 with more recent treatment techniques.

Lastly, Wettstein et al. (53) have published data on survival outcomes among MIBC patients treated by either TMT or RC, including only 12 studies for analysis. Pooled results were significantly in favour of RC. However, the authors highlight that results might be driven by large population-based studies. Further 
research is expected in order to have a remarkable impact on the estimate of treatment effect.

Propensity score matching analyses have been published aiming to control for confounding factors within cohorts. The Fox Chase group analysed the NCDB (National Cancer Database) (54) including patients with stage II-III MIBC between 2004 and 2013. The authors reported 5-year OS of $48.3 \%$ in the RC group, whereas TMT cohort had 29.9\%. When confounding factors were controlled RC benefits in OS were attenuated compared to TMT. Kulkarni et al. (8) reported results after propensity score analysis in the Toronto Multidisciplinary Bladder Cancer Clinic. At the time of analysis, extent of TURBT, presence of hydronephrosis, presence of CIS and comorbidities were taken into account. A total of 112 MIBC patients were included after matching. With a median follow-up of 4.5 years, 5 -year CSS was similar between groups (76.6\% vs $73.2 \%$ ). The SC rate in the TMT group was $10.7 \%$. The single institution study and the retrospective selection bias are part of the limitations.

To date, published data comparing TMT and RC should be interpreted with caution due to inherent bias in retrospective comparative studies. Proper RCTs are needed to achieve more robust data in order to support the non-inferiority in selected MIBC patients.

\subsection{Limitations and future aspects}


TMT is nowadays a well-established bladder preservation strategy in selected patients with MIBC. In many countries and for instance in Ontario, Canada, rates of referral to radiation oncologists are increasing (31\% in 2009 to $37 \%$ in 2013) (55). Limitations inherent to TMT are the risk of bladder recurrences (often non muscle invasive and manageable conservatively) and progression of the disease outside of the retained bladder; inability to assess outcomes of patients with other than transitional cell carcinoma subtypes or the potential for non-inferiority survival outcomes; the need for chemo-RT regimens optimization and establishing the role of NAC within the current protocols.

Very few data have been published on biomarkers within the TMT population. The MGH group (56) reported on the prognostic value of immune and stromal infiltration in MIBC treated with TMT. Significant associations after transcriptional profiling of tumors in MIBC patients are described. They stated that after TMT a higher immune infiltration was associated with better DSS, whereas after NAC and RC the opposite effect is seen.

Several planned or ongoing clinical trials of bladder preservation therapy for MIBC have incorporated molecular biomarkers into their trial design. The SWOG S1806 trial will randomly assign patients with muscle-invasive bladder cancer to chemoradiation with or without the anti-PD-L1 checkpoint inhibitor atezolizumab, and will include transcriptional profiling and comprehensive genomic analysis of all samples (57).

Additional studies should be performed to determine if treatment response can be predicted by gene expression profiling in this subgroup population. 
Currently, several novel systemic therapies are being tested, which either include monoclonal antibodies or immune checkpoint inhibitors. The recently published phase I/II RCT RTOG 0524 (43) evaluated the addition of trastuzumab to paclitaxel in patients with her2/neu positive MIBC as a radio-sensitizing agent. Immunotherapy has seen a revolution in all areas of cancer treatment, especially in BC. Anti-tumour response may be strengthened by monoclonal antibodies targeting programmed death ligand-1 (PDL-1) / programmed death-1 (PD-1). Immune checkpoint inhibitors have been approved as a first line treatment option for metastatic cisplatin-ineligible MIBC patients. Phase I/II trials are currently accruing patients with MIBC on TMT protocols. Table 4 illustrates some of the ongoing clinical trials including immune checkpoint inhibitors $(58,59)$.

\section{Conclusions}

Several management options are available when bladder preservation is attempted for MIBC. Proper patient selection is key to successful management in this setting. No homogenous inclusion criteria for bladder preservation are reported, however, this approach is best offered to the following candidates: low volume T2 tumour, no or moderate unilateral hydronephrosis, no extensive multifocal CIS and good bladder function. Nowadays the tri-modal approach (maximum TURBT followed by concurrent chemo-RT) is the most strongly supported strategy in published data. No randomized controlled studies are available comparing radical cystectomy and TMT but the two treatment options 
seem to provide similar long-term outcomes when TMT is offered in carefully selected patients while maintaining an excellent quality of life.

\section{References}

1. Siegel RL, Miller KD, Jemal A. Cancer statistics, 2020. CA Cancer J Clin. 2020 Jan 8;70(1):7-30.

2. Witjes JA, Bruins M, Cathomas R, Compérat E, Cowan NC, Gakis G, et al. EAU Guidelines on and Metastatic Bladder Cancer. 2019;

3. Brassetti A, Tuderti G, Anceschi U, Ferriero M, Guaglianone S, Gallucci $\mathrm{M}$, et al. Combined reporting of surgical quality, cancer control and functional outcomes of robot-assisted radical cystectomy with 
intracorporeal orthotopic neobladder into a novel trifecta. In: Minerva Urologica e Nefrologica. Edizioni Minerva Medica; 2019. p. 590-6.

4. Porreca A, Chessa F, Romagnoli D, Salvaggio A, Cafarelli A, Borghesi M, et al. Robot assisted radical cystectomy with totally intracorporeal urinary diversion: Initial, single-surgeon's experience after a modified modular training. Minerva Urol e Nefrol. 2018 Apr 1;70(2):193-201.

5. Giannarini G, Crestani A, Inferrera A, Rossanese M, Subba E, Novara G, et al. Impact of enhanced recovery after surgery protocols versus standard of care on perioperative outcomes of radical cystectomy: a systematic review and meta-analysis of comparative studies. Vol. 71, Minerva Urologica e Nefrologica. Edizioni Minerva Medica; 2019. p. 309-23.

6. Donat SM, Shabsigh A, Savage C, Cronin AM, Bochner BH, Dalbagni G, et al. Potential Impact of Postoperative Early Complications on the Timing of Adjuvant Chemotherapy in Patients Undergoing Radical Cystectomy: A High-Volume Tertiary Cancer Center Experience. Eur Urol. 2009;55(1):177-86.

7. Shabsigh A, Korets R, Vora KC, Brooks CM, Cronin AM, Savage C, et al. Defining Early Morbidity of Radical Cystectomy for Patients with Bladder Cancer Using a Standardized Reporting Methodology. Eur Urol. 2009;55(1):164-76.

8. Kulkarni GS, Hermanns T, Wei Y, Bhindi B, Satkunasivam R, Athanasopoulos $\mathrm{P}$, et al. Propensity score analysis of radical cystectomy 
versus bladder-sparing trimodal therapy in the setting of a multidisciplinary bladder cancer clinic. In: Journal of Clinical Oncology. 2017. p. 2299-305.

9. Ploussard G, Daneshmand S, Efstathiou JA, Herr HW, James ND, Rödel $\mathrm{CM}$, et al. Critical analysis of bladder sparing with trimodal therapy in muscle-invasive bladder cancer: A systematic review. Vol. 66, European Urology. 2014. p. 120-37.

10. Arcangeli G, Arcangeli S, Strigari L. A systematic review and metaanalysis of clinical trials of bladder-sparing trimodality treatment for muscle-invasive bladder cancer ( MIBC ). Crit Rev Oncol / Hematol. 2015;94(1):105-15.

11. Smith ZL, Christodouleas JP, Keefe SM, Malkowicz SB, Guzzo TJ. Bladder preservation in the treatment of muscle-invasive bladder cancer (MIBC): A review of the literature and a practical approach to therapy. Vol. 112, BJU International. 2013. p. 13-25.

12. James ND, Hussain S a, Hall E, Jenkins P, Tremlett J, Rawlings C, et al. Radiotherapy with or without chemotherapy in muscle-invasive bladder cancer. N Engl J Med. 2012;366(16):1477-88.

13. Shipley WU, Winter KA, Kaufman DS, Lee WR, Heney NM, Tester WR, et al. Phase III trial of neoadjuvant chemotherapy in patients with invasive bladder cancer treated with selective bladder preservation by combined radiation therapy and chemotherapy: initial results of Radiation Therapy 
Oncology Group 89-03. J Clin Oncol. 1998 Nov;16(11):3576-83.

14. Coen JJ, Zhang P, Saylor PJ, Lee CT, Wu CL, Parker W, et al. Bladder preservation with twice-a-day radiation plus fluorouracil/cisplatin or once daily radiation plus gemcitabine for muscle-invasive bladder cancer: NRG/RTOG 0712 - a randomized phase II trial. In: Journal of Clinical Oncology. 2019. p. 44-51.

15. Mak RH, Hunt D, Shipley WU, Efstathiou JA, Tester WJ, Hagan MP, et al. Long-term outcomes in patients with muscle-invasive bladder cancer after selective bladder-preserving combined-modality therapy: A pooled analysis of radiation therapy oncology group protocols 8802, 8903, 9506, 9706, 9906, and 0233. J Clin Oncol. 2014;32(34):3801-9.

16. Zapatero A, Martin De Vidales C, Arellano R, Ibañez Y, Bocardo G, Perez M, et al. Long-term results of two prospective bladder-sparing trimodality approaches for invasive bladder cancer: Neoadjuvant chemotherapy and concurrent radio-chemotherapy. Urology. 2012 Nov;80(5):1056-62.

17. Tunio MA, Hashmi A, Qayyum A, Mohsin R, Zaeem A. Whole-pelvis or bladder-only chemoradiation for lymph node-negative invasive bladder cancer: Single-institution experience. Vol. 82, International Journal of Radiation Oncology Biology Physics. Elsevier Inc; 2012. p. e457-62.

18. Choudhury A, Swindell R, Logue JP, Elliott PA, Livsey JE, Wise M, et al. Phase II study of conformal hypofractionated radiotherapy with concurrent gemcitabine in muscle-invasive bladder cancer. $\mathrm{J}$ Clin Oncol. 
2011;29(6):733-8.

19. Kaufman DS, Winter KA, Shipley WU, Heney NM, Wallace HJ, Toonkel LM, et al. Phase I-II RTOG Study (99-06) of Patients With MuscleInvasive Bladder Cancer Undergoing Transurethral Surgery, Paclitaxel, Cisplatin, and Twice-daily Radiotherapy Followed by Selective Bladder Preservation or Radical Cystectomy and Adjuvant Chemotherapy. Urology. 2009;73(4):833-7.

20. Gogna NK, Matthews JHL, Turner SL, Mameghan H, Duchesne GM, Spry $\mathrm{N}$, et al. Efficacy and tolerability of concurrent weekly low dose cisplatin during radiation treatment of localised muscle invasive bladder transitional cell carcinoma: A report of two sequential Phase II studies from the Trans Tasman Radiation Oncology Group. Radiother Oncol. 2006;81(1):9-17.

21. Housset M, Maulard C, Chretien Y, Dufour B, Delanian S, Huart J, et al. Combined radiation and chemotherapy for invasive transitional-cell carcinoma of the bladder: a prospective study. J Clin Oncol. 1993 Nov;11(11):2150-7.

22. Büchser D, Zapatero A, Rogado J, Talaya M, Martín de Vidales C, Arellano R, et al. LONG TERM OUTCOMES AND PATTERNS OF FAILURE FOLLOWING TRIMODALITY TREATMENT WITH BLADDER PRESERVATION FOR INVASIVE BLADDER CANCER. Urology. 2018 Sep 25.

23. Giacalone NJ, Shipley WU, Clayman RH, Niemierko A, Drumm M, 
Heney NM, et al. Long-term Outcomes After Bladder-preserving Trimodality Therapy for Patients with Muscle-invasive Bladder Cancer: An Updated Analysis of the Massachusetts General Hospital Experience. Eur Urol. 2017;1-9.

24. Caffo O, Thompson C, De Santis M, Kragelj B, Hamstra DA, Azria D, et al. Concurrent gemcitabine and radiotherapy for the treatment of muscleinvasive bladder cancer: A pooled individual data analysis of eight phase I-II trials. Radiother Oncol. 2016;121(2):193-8.

25. Krause FS, Walter B, Ott OJ, Häberle L, Weiss C, Rödel C, et al. 15-Year Survival Rates After Transurethral Resection and Radiochemotherapy or Radiation in Bladder Cancer Treatment. Anticancer Res. 2011;31(3):98590.

26. Perdonà S, Autorino R, Damiano R, De Sio M, Morrica B, Gallo L, et al. Bladder-sparing, combined-modality approach for muscle-invasive bladder cancer: A multi-institutional, long-term experience. Cancer. 2008;112(1):76-83.

27. Weiss C, Engehausen DG, Krause FS, Papadopoulos T, Dunst J, Sauer R, et al. Radiochemotherapy With Cisplatin and 5-Fluorouracil After Transurethral Surgery in Patients With Bladder Cancer. Int J Radiat Oncol Biol Phys. 2007;68(4):1072-80.

28. Chung PWM, Bristow RG, Milosevic MF, Yi Q long, Jewett MAS, Warde PR, et al. Long-term outcome of radiation-based conservation therapy for 
invasive bladder cancer. Urol Oncol Semin Orig Investig. 2007;25(4):3039.

29. Hussain SA, Stocken DD, Peake DR, Glaholm JG, Zarkar A, Wallace DMA, et al. Long-term results of a phase II study of synchronous chemoradiotherapy in advanced muscle invasive bladder cancer. $\mathrm{Br} \mathrm{J}$ Cancer. 2004 Jun 1;90(11):2106-11.

30. Rödel C, Grabenbauer GG, Kühn R, Papadopoulos T, Dunst J, Meyer M, et al. Combined-modality treatment and selective organ preservation in invasive bladder cancer: Long-term results. J Clin Oncol. 2002;20(14):3061-71.

31. Sanchez A, Wszolek MF, Niemierko A, Clayman RH, Drumm M, Rodríguez D, et al. Incidence, Clinicopathological Risk Factors, Management and Outcomes of Nonmuscle Invasive Recurrence after Complete Response to Trimodality Therapy for Muscle Invasive Bladder Cancer. J Urol. 2018;199(2):407-15.

32. Weiss C, Wittlinger M, Engehausen DG, Krause FS, Ott OJ, Dunst J, et al. Management of Superficial Recurrences in an Irradiated Bladder After Combined-Modality Organ-Preserving Therapy. Int J Radiat Oncol Biol Phys. 2008;70(5):1502-6.

33. Zietman AL, Grocela J, Zehr E, Kaufman DS, Young RH, Althausen AF, et al. Selective bladder conservation using transurethral resection, chemotherapy, and radiation: Management and consequences of TA, T1, 
and TIS recurrence within the retained bladder. Urology. 2001;58(3):3805.

34. Zietman AL, Sacco D, Skowronski U, Gomery P, Kaufman DS, Clark JA, et al. Organ conservation in invasive bladder cancer by transurethral resection, chemotherapy and radiation: Results of a urodynamic and quality of life study on long-term survivors. J Urol. 2003;170(5):1772-6.

35. Herman JM, Smith DC, Montie J, Hayman JA, Sullivan MA, Kent E, et al. Prospective quality-of-life assessment in patients receiving concurrent gemcitabine and radiotherapy as a bladder preservation strategy. Vol. 64, Urology. 2004. p. 69-73.

36. Mak KS, Smith AB, Eidelman A, Clayman R, Niemierko A, Cheng J, et al. Quality of Life in Long-term Survivors of Muscle-Invasive Bladder Cancer. Radiat Oncol Biol. 2016;96(5):1028-36.

37. Lagrange JL, Bascoul-Mollevi C, Geoffrois L, Beckendorf V, Ferrero JM, Joly F, et al. Quality of life assessment after concurrent chemoradiation for invasive bladder cancer: Results of a multicenter prospective study (getug 97-015). Int J Radiat Oncol Biol Phys. 2011;79(1):172-8.

38. Huddart RA, Hall E, Lewis R, Porta N, Crundwell M, Jenkins PJ, et al. Patient-reported Quality of Life Outcomes in Patients Treated for Muscleinvasive Bladder Cancer with Radiotherapy \pm Chemotherapy in the BC2001 Phase III Randomised Controlled Trial[Formula presented]. Eur Urol. 2020 Feb 1;77(2):260-8. 
39. Hagan MP, Winter KA, Kaufman DS, Wajsman Z, Zietman AL, Heney NM, et al. REPORT OF A PHASE I-II TRIAL OF SELECTIVE BLADDER CONSERVATION USING TURBT, TWICE-DAILY ACCELERATED IRRADIATION SENSITIZED WITH CISPLATIN, AND ADJUVANT MCV COMBINATION CHEMOTHERAPY. Int $\mathbf{J}$ Radiat Oncol Biol Phys. 2003;57(3):665-72.

40. Hautmann RE, De Petriconi RC, Pfeiffer C, Volkmer BG. Radical cystectomy for urothelial carcinoma of the bladder without neoadjuvant or adjuvant therapy: Long-term results in 1100 patients. Eur Urol. 2012 May 1;61(5):1039-47.

41. Goldsmith B, Baumann BC, He J, Tucker K, Bekelman J, Deville C, et al. Occult Pelvic Lymph Node Involvement in Bladder Cancer: Implications for Definitive Radiation Radiation Oncology. Radiat Oncol Biol. 2014;88(3):603-10.

42. Grossman HB, Natale RB, Tangen CM, Speights VO, Vogelzang NJ, Trump DL, et al. Neoadjuvant Chemotherapy plus Cystectomy Compared with Cystectomy Alone for Locally Advanced Bladder Cancer. N Engl J Med. 2003 Aug 28;349(9):859-66.

43. Michaelson MD, Hu C, Pham HT, Dahl DM, Lee-Wu C, Swanson GP, et al. A Phase 1/2 Trial of a Combination of Paclitaxel and Trastuzumab With Daily Irradiation or Paclitaxel Alone With Daily Irradiation After Transurethral Surgery for Noncystectomy Candidates With Muscle- 
Invasive Bladder Cancer (Trial NRG Oncology RTOG 0524). Int J Radiat Oncol Biol Phys. 2017;97(5):995-1001.

44. Vale CL. Neoadjuvant chemotherapy in invasive bladder cancer: Update of a systematic review and meta-analysis of individual patient data. Vol. 48, European Urology. Elsevier; 2005. p. 202-6.

45. Jiang D (Maria), Jiang H, Chung PWM, Zlotta AR, Fleshner NE, Bristow RG, et al. Neoadjuvant Chemotherapy Before Bladder-Sparing Chemoradiotherapy in Patients With Nonmetastatic Muscle-Invasive Bladder Cancer. Clin Genitourin Cancer. 2019 Feb;17(1):38-45.

46. Fahmy O, Khairul-Asri MG, Schubert T, Renninger M, Malek R, Kübler $\mathrm{H}$, et al. A systematic review and meta-analysis on the oncological longterm outcomes after trimodality therapy and radical cystectomy with or without neoadjuvant chemotherapy for muscle-invasive bladder cancer. Urol Oncol Semin Orig Investig. 2018;36(2):43-53.

47. Winquist E, Booth CM. Trimodality Therapy for Muscle-Invasive Bladder Cancer: Concurrent Chemotherapy is Not Enough. J Clin Oncol. 2020 May 27;JCO.19.02959.

48. Ajib K, Tjong M, Lunsky I, Tan GH, Nason G, Erlich A, et al. Impact of neoadjuvant chemotherapy on bladder recurrences in patients managed with trimodal therapy (TMT) for muscle-invasive bladder cancer. Eur Urol Suppl. 2019 Mar 1;18(1):e2115.

49. Lin HY, Ye H, Kernen KM, Hafron JM, Krauss DJ. National Cancer 
Database Comparison of Radical Cystectomy vs Chemoradiotherapy for Muscle-Invasive Bladder Cancer: Implications of Using Clinical vs Pathologic Staging. Cancer Med. 2018;(May):5370-81.

50. Huddart RA, Birtle A, Maynard L, Beresford M, Blazeby J, Donovan J, et al. Clinical and patient-reported outcomes of SPARE - a randomised feasibility study of selective bladder preservation versus radical cystectomy. BJU Int. 2017;120(5):639-50.

51. Arcangeli G, Strigari L, Arcangeli S. Radical cystectomy versus organsparing trimodality treatment in muscle-invasive bladder cancer: A systematic review of clinical trials. Crit Rev Oncol Hematol. 2015;95(3):387-96.

52. Vashistha V, Wang H, Mazzone A, Liss MA, Svatek RS, Schleicher M, et al. Radical Cystectomy Compared to Combined Modality Treatment for Muscle-Invasive Bladder Cancer: A Systematic Review and MetaAnalysis. Int J Radiat Oncol Biol Phys. 2017;97(5):1002-20.

53. Wettstein MS, Rooprai JK, Pazhepurackel C, Wallis CJD, Klaassen Z, Uleryk EM, et al. Systematic review and meta-analysis on trimodal therapy versus radical cystectomy for muscle-invasive bladder cancer: Does the current quality of evidence justify definitive conclusions? PLoS One. 2019;14(4):1-18.

54. Cahn DB, Handorf EA, Ghiraldi EM, Ristau BT, Geynisman DM, Churilla TM, et al. Contemporary use trends and survival outcomes in patients 
undergoing radical cystectomy or bladder-preservation therapy for muscleinvasive bladder cancer. Cancer. 2017;123(22):4337-45.

55. Wei X, Siemens DR, Mackillop WJ, Booth CM. Use of radiotherapy for bladder cancer: A population-based study of evolving referral and practice patterns. Can Urol Assoc J. 2018 Sep 25;13(4).

56. Efstathiou JA, Mouw KW, Gibb EA, Liu Y, Wu CL, Drumm MR, et al. Impact of Immune and Stromal Infiltration on Outcomes Following Bladder-Sparing Trimodality Therapy for Muscle-Invasive Bladder Cancer. Eur Urol. 2019;76(1):59-68.

57. Miyamoto DT, Mouw KW, Feng FY, Shipley WU, Efstathiou JA. Molecular biomarkers in bladder preservation therapy for muscle-invasive bladder cancer. Vol. 19, The Lancet Oncology. Lancet Publishing Group; 2018. p. e683-95.

58. Rijnders M, de Wit R, Boormans JL, Lolkema MPJ, van der Veldt AAM. Systematic Review of Immune Checkpoint Inhibition in Urological Cancers. Eur Urol. 2017;72(3):411-23.

59. Murali-Krishnan S, Pang KH, Greco F, Fiori C, Catto JW, Vavassori VL, et al. Bladder-sparing treatment in MIBC: Where do we stand? Vol. 71, Minerva Urologica e Nefrologica. Edizioni Minerva Medica; 2019. p. 10112.

\section{Authors' contribution}

Review concept and design: Polo-Alonso, Mir, Kuk, Zlotta. 
Drafting of the manuscript: Polo-Alonso, Mir, Kuk, Zlotta.

Critical revision of the manuscript: Mir, Zlotta, Guruli, Paul, Kamat, Solsona, Thalmann, Urdaneta.

Supervision: Mir, Zlotta.

All authors read and approved the final version of the manuscript.

Figure 1. PRISMA diagram detailing study selection
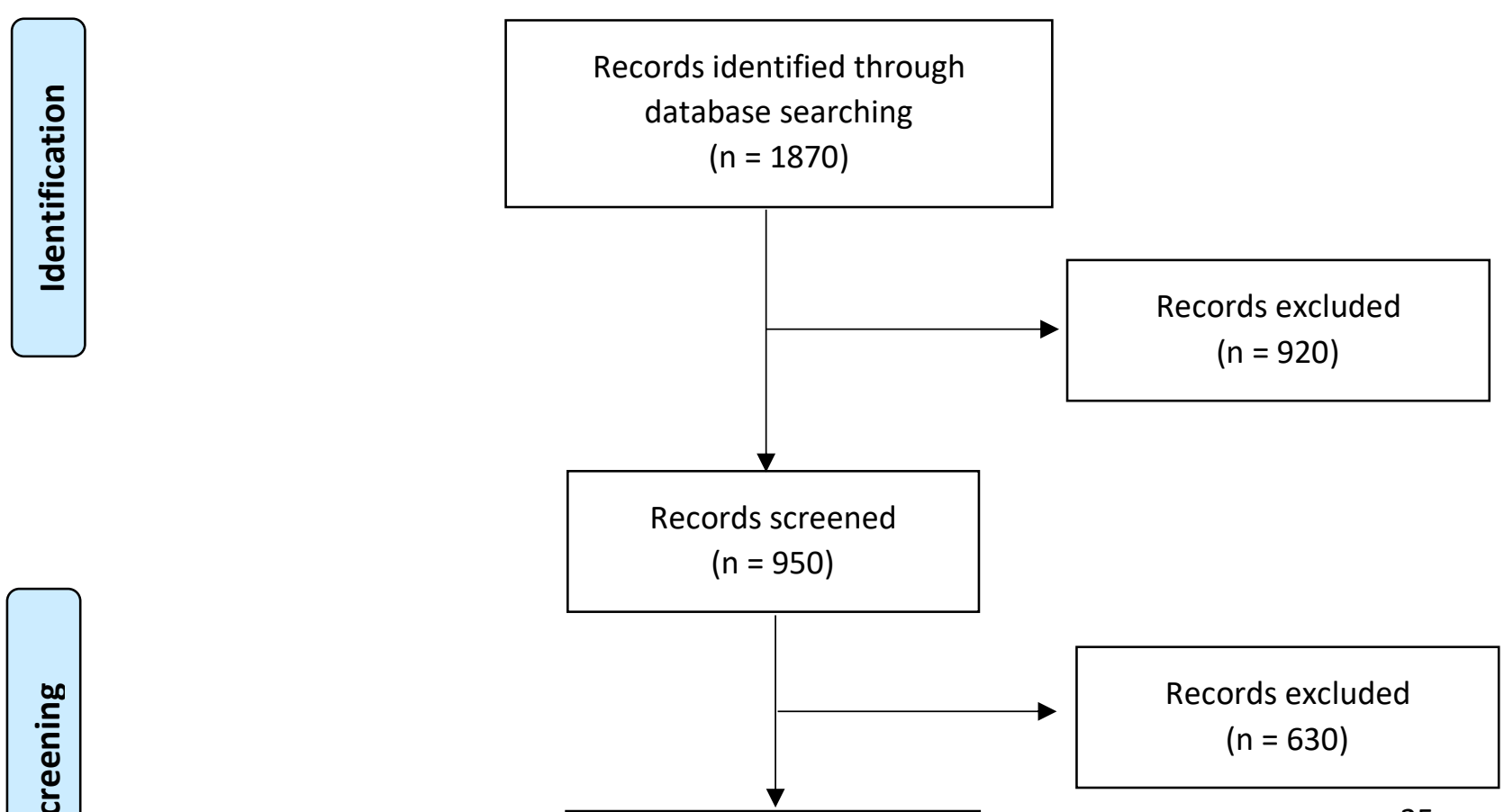

Records reviewed by abstract 
Table 1. Currently Published Data on TMT for Curative Intent in MIBC

\begin{tabular}{|c|c|c|c|c|c|c|c|c|c|c|}
\hline Author & $\begin{array}{l}\text { Follow up } \\
\quad(\mathrm{mo})\end{array}$ & $\begin{array}{l}\text { Median } \\
\text { age }(y)\end{array}$ & Clinical stage & $\begin{array}{l}\text { Radiosensitizing } \\
\text { Chemotherapy }\end{array}$ & $\begin{array}{c}\text { RT } \\
\text { Dosing } \\
\text { (Gy) }\end{array}$ & $\begin{array}{l}\text { NAC } \\
(\mathbf{Y} / \mathbf{N})\end{array}$ & $\begin{array}{c}\text { CR rate } \\
(\%)\end{array}$ & $\begin{array}{c}\text { SC } \\
\text { n }(\%)\end{array}$ & $\begin{array}{c}5 y \\
\text { CSS } \\
(\%)\end{array}$ & $\begin{array}{c}5 y \\
\text { OS }(\%)\end{array}$ \\
\hline \multicolumn{11}{|c|}{ Phase III Randomized Control Trials } \\
\hline $\begin{array}{c}\text { James et al., } 2012(12) \\
\mathrm{n}=182\end{array}$ & 70 & $\begin{array}{c}72 \\
(65-76)\end{array}$ & $\begin{array}{l}\text { cT2-T4a } \\
\text { N0 }\end{array}$ & $\begin{array}{c}\text { 5-FU, } \\
\mathrm{MMCx} 2\end{array}$ & $55-64$ & $\begin{array}{l}\text { Yes: } 57 \\
\text { No: } 125\end{array}$ & NS & $6(11)$ & 67 & 48 \\
\hline $\begin{array}{c}\text { Shipley et al., } 1998 \\
(13) \\
n=62(\operatorname{arm} 2) \\
\end{array}$ & 60 & NS & cT2-T4a N0/Nx & Cisplatin $\mathrm{x} 3$ & 64.8 & No & 55 & $(26)$ & NS & 49 \\
\hline \multicolumn{11}{|c|}{ Phase II Prospective Clinical Trials } \\
\hline $\begin{array}{c}\text { Coen et al., } \\
2019(14) \\
n=66\end{array}$ & 61 & NS & cT2-T4a & $\begin{array}{c}\text { 5-FU+Cisplatin (FCT) } \\
\text { Vs } \\
\text { Gemcitabine (GD) }\end{array}$ & Several & No & $\begin{array}{c}\text { FCT: } 88 \\
\text { GD:78 }\end{array}$ & $\begin{array}{c}8(12) \\
\text { FCT: } 3 \\
\text { GD: } 5\end{array}$ & NS & NS \\
\hline $\begin{array}{c}\text { Mak et al., } 2014 \\
\text { (RTOG) (15) } \\
n=468\end{array}$ & 50 & $\begin{array}{c}66 \\
(34-93)\end{array}$ & cT2-T4a & Several & Several & $\begin{array}{c}\text { Yes: } \\
151 \\
\text { No: } 317 \\
\end{array}$ & 69 & $\begin{array}{l}100 \\
(21)\end{array}$ & 71 & 57 \\
\hline $\begin{array}{c}\text { Zapatero et al., } 2012 \\
\qquad \begin{array}{c}(16) \\
\mathrm{n}=80\end{array}\end{array}$ & 72 & $\begin{array}{c}62 \\
(41-76)\end{array}$ & $\begin{array}{l}\text { cT2-T4a } \\
\text { N0 }\end{array}$ & $\begin{array}{l}\text { Weekly cisplatin } \\
(\mathrm{n}=5 \text { paclitaxel) }\end{array}$ & 64.8 & $\begin{array}{l}\text { Yes: } 41 \\
\text { No: } 39\end{array}$ & 74 & $17(21)$ & 82 & 73 \\
\hline $\begin{array}{c}\text { Tunio et al., } 2012 \text { (17) } \\
\mathrm{n}=230\end{array}$ & 60 & 62 & cT2-T4a N0/Nx & Weekly cisplatin & 65 & No & 93 & $70(30)$ & $\begin{array}{l}\text { WP: } \\
47.1 \\
\text { BO: } \\
46.9\end{array}$ & $\begin{array}{l}\text { WP: } 53 \\
\text { BO: } 51\end{array}$ \\
\hline $\begin{array}{c}\text { Choudhury et al., } 2011 \\
\qquad \begin{array}{c}(18) \\
\mathrm{n}=50\end{array}\end{array}$ & 36 & $\begin{array}{c}67 \\
(48-84)\end{array}$ & cT2-T3 N0/Nx & Weekly gemcitabine & 52.5 & No & 88 & $4(8)$ & $3 y: 82$ & $3 y: 75$ \\
\hline $\begin{array}{c}\text { Kaufman et al., } 2009 \\
(19) \\
n=80\end{array}$ & 49 & NS & $\begin{array}{l}\text { cT2-T4a } \\
\text { N0 }\end{array}$ & $\begin{array}{l}\text { Weekly cisplatin }+ \\
\text { Paclitaxel x } 5\end{array}$ & 64 & No & 81 & $10(12)$ & 71 & 56 \\
\hline
\end{tabular}




\begin{tabular}{|c|c|c|c|c|c|c|c|c|c|c|}
\hline $\begin{array}{c}\text { Gogna et al., } 2006 \\
(20) \\
\mathrm{n}=113\end{array}$ & 23 & NS & $\begin{array}{c}\text { cT2-T4a } \\
\text { high risk } \mathrm{T} 1\end{array}$ & Weekly Cisplatin & 64 & No & 70 & $15(13)$ & 50 & NS \\
\hline $\begin{array}{l}\text { Housset et al., } 1993 \\
\qquad \begin{array}{c}(21) \\
n=54\end{array}\end{array}$ & 27 & $\begin{array}{c}66 \\
(37-82)\end{array}$ & $\begin{array}{c}\text { cT2-T4a } \\
\text { N0/N1(n:4) }\end{array}$ & Cisplatin $+5-\mathrm{FU} \times 4$ & 44 & No & 74 & NS & $3 y: 62$ & $3 y: 59$ \\
\hline \multicolumn{11}{|c|}{ Prospective / Retrospective Single Institutions } \\
\hline $\begin{array}{c}\text { Büchser et al., } 2018 \\
(22) \\
n=90\end{array}$ & 94 & $\begin{array}{c}63 \\
(41-77)\end{array}$ & cT2-T4a & Several & Several & $\begin{array}{l}\text { Yes: } 42 \\
\text { No: } 48\end{array}$ & 79 & $19(21)$ & 81.4 & 67.1 \\
\hline $\begin{array}{c}\text { Giacalone et al., } 2017 \\
(\mathrm{MGH})(23) \\
\mathrm{n}=475\end{array}$ & 85 & $\begin{array}{c}67.3 \\
(60.2-74.6)\end{array}$ & cT2-T4a N0M0 & Several & Several & Several & 75 & $\begin{array}{l}129 \\
(27)\end{array}$ & 66 & 57 \\
\hline $\begin{array}{c}\text { Caffo et al., } 2016(24) \\
n=190\end{array}$ & 44 & $\begin{array}{c}70 \\
(42-87)\end{array}$ & cT2-T4a & Gemcitabine & Several & No & 93 & $14(7)$ & 80.9 & 59 \\
\hline $\begin{array}{c}\text { Krause et al., } 2011 \\
(25) \\
\mathrm{n}=473 \\
\end{array}$ & 71 & $\begin{array}{c}65.3 \\
(28-91)\end{array}$ & cT2-T4a N0/Nx & $\begin{array}{c}\text { Various } \\
\text { RT alone: } 142\end{array}$ & Several & No & 70.4 & NS & NS & 49 \\
\hline $\begin{array}{c}\text { Perdonà et al., } 2008 \\
(26) \\
n=121\end{array}$ & 66 & 63 & $\begin{array}{l}\text { cT2-T4a } \\
\text { N0/Nx }\end{array}$ & $\begin{array}{c}\text { Cisplatin } \\
(\mathrm{n}=25 \text { Carboplatin })\end{array}$ & 65 & Yes & 85.7 & $\begin{array}{c}24 \\
(20.2)\end{array}$ & 73.5 & 67.7 \\
\hline $\begin{array}{l}\text { Weiss et al., } 2007 \text { (27) } \\
\qquad \mathrm{n}=112\end{array}$ & 27 & 64 & $\begin{array}{c}\text { cT2-T4a N0/Nx } \\
(58) \\
\mathrm{T} 1(54) \\
\end{array}$ & Cisplatin + 5-FU x2 & $\begin{array}{l}55.8- \\
59.4\end{array}$ & No & 88.4 & 19 (17) & $\begin{array}{c}82 \\
(\mathrm{~T} 2- \\
\mathrm{T} 4: 73) \\
\end{array}$ & $\begin{array}{r}74 \\
(\mathrm{~T} 2- \\
\mathrm{T} 4: 63) \\
\end{array}$ \\
\hline $\begin{array}{l}\text { Chung et al., } 2007 \\
\begin{array}{c}(28) \\
n=340\end{array}\end{array}$ & 90 & $\begin{array}{c}71 \\
(35-91)\end{array}$ & $\mathrm{cT} 2-\mathrm{T} 4$ & $\begin{array}{c}\text { Cisplatin } \\
\text { (Neoadjuvant CT+RT: } \\
57 \\
\text { RTalone:247) }\end{array}$ & Several & $\begin{array}{l}\text { Yes: } 57 \\
\text { No: } 283\end{array}$ & 63.5 & $57(17)$ & 42 & 32 \\
\hline $\begin{array}{c}\text { Hussain et al., } 2004 \\
(29) \\
n=41\end{array}$ & 51 & $\begin{array}{c}68 \\
(58-77)\end{array}$ & $\begin{array}{c}\text { cT2-T4a N0/Nx } \\
\text { M0 }\end{array}$ & $\begin{array}{l}\mathrm{MMC}+ \\
5-\mathrm{FU} \times 2\end{array}$ & 55 & No & 71 & $5(12)$ & $2 y: 68$ & 36 \\
\hline $\begin{array}{c}\text { Rödel et al., } 2002 \text { (30) } \\
\text { (Erlangen) } \\
n=415\end{array}$ & 60 & $\begin{array}{c}67 \\
(31-89)\end{array}$ & cT1-T4a & $\begin{array}{c}\text { Several } \\
\text { RT alone:126 }\end{array}$ & Several & No & 72 & $83(20)$ & 56 & 51 \\
\hline
\end{tabular}


RT: radiotherapy. NAC (Y/N): neoadjuvant chemotherapy (yes/no). CR: complete response. SC: Salvage Cystectomy; 5y CSS: 5-year cancer specific survival. 5y OS: 5-year overall survival. NS: non stated. 5-FU: 5-fluoruracil. MMC: mytomicin. FCT: Fluorouracil plus cisplatin and radiation twice a day. GD: Gemcitabine and once daily radiation. P1: protocol 1, neoadjuvant methotrexate, cisplatin and vinblastine (MCV). P2: protocol 2, cisplatin and concurrent radiotherapy. WP: whole pelvis concurrent chemoradiation (CCRT). BO: bladder-only CCRT.

Table 2. Largest Series on Recurrences Rates Location After Curative Intent with TMT and MIBC

\begin{tabular}{|c|c|c|c|c|c|c|}
\hline Author & Follow up (mo) & $\begin{array}{l}\mathrm{MIBC} \\
\mathrm{n}(\%)\end{array}$ & $\begin{array}{c}\text { NMIBC } \\
\mathrm{n}(\%)\end{array}$ & $\begin{array}{l}\text { Local Recurrence } \\
(\%)\end{array}$ & $\begin{array}{c}\text { Pelvic Node Recurrence } \\
\mathrm{n}(\%)\end{array}$ & $\begin{array}{c}\text { Metastatic After CR } \\
(\%)\end{array}$ \\
\hline $\begin{array}{c}\text { Coen et al., } \\
2019(14) \\
n=66\end{array}$ & 60 & NS & NS & NS & NS & $\begin{array}{l}\text { FCT: } 22 \\
\text { GD: } 16 \\
(@ 3 y)\end{array}$ \\
\hline $\begin{array}{l}\text { Büchser et al., } 2018 \text { (22) } \\
n=90\end{array}$ & 94 & $3(4)$ & $11(15)$ & 15 & NS & 15 \\
\hline $\begin{array}{c}\text { Giacalone et al., } 2017 \text { (MGH) (23) } \\
n=475\end{array}$ & 80 & $76(16)$ & $123(26)$ & 42 & $57(12)$ & 32 \\
\hline $\begin{array}{c}\text { Caffo et al., } 2016 \text { (24) } \\
n=190\end{array}$ & 44 & $9(5)$ & $19(10)$ & 19 & NS & 16 \\
\hline $\begin{array}{c}\text { Mak et al., } 2014 \\
\text { (RTOG) }(15) \\
n=468\end{array}$ & 50 & $\begin{array}{l}5 y:(13) \\
10 y:(14)\end{array}$ & $\begin{array}{l}5 y: 31 \\
10 y: 36\end{array}$ & $\begin{array}{c}\text { Any } \\
5 y: 43 \\
10 y: 48\end{array}$ & $\begin{array}{l}5 y: 13 \\
10 y: 16\end{array}$ & $\begin{array}{l}5 y: 31 \\
10 y: 35\end{array}$ \\
\hline $\begin{array}{l}\text { James et al., } 2012(12) \\
\mathrm{n}=182\end{array}$ & 70 & $20(11)$ & $26(14.3)$ & 18 & $9(5)$ & NS \\
\hline $\begin{array}{c}\text { Tunio et al., } 2012 \text { (17) } \\
\mathrm{n}=230\end{array}$ & 60 & $\begin{array}{l}\text { WP: } 20(57) \\
\text { BO: } 19(54)\end{array}$ & $\begin{array}{l}\text { WP: } 18(19) \\
\text { BO: } 19(21)\end{array}$ & $\begin{array}{l}\text { WP: } 41 \\
\text { BO: } 43\end{array}$ & $\begin{array}{l}\text { WP: } 15(43) \\
\text { BO: } 16(46)\end{array}$ & $\begin{array}{l}\text { WP: } 18 \\
\text { BO: } 18\end{array}$ \\
\hline $\begin{array}{l}\text { Choudhury et al., } 2011 \text { (18) } \\
n=50\end{array}$ & 36 & $2(4)$ & $3(6)$ & 10 & $5(10)$ & 4 \\
\hline $\begin{array}{l}\text { Kaufman et al., } 2009 \text { (19) } \\
n=80\end{array}$ & 49 & $8(12)$ & $7(9)$ & 29 & $9(11)$ & 31 \\
\hline $\begin{array}{l}\text { Perdonà et al., } 2008 \text { (26) } \\
\mathrm{n}=121\end{array}$ & 66 & $18(17)$ & $17(16)$ & 29 & NS & 28 \\
\hline
\end{tabular}




\begin{tabular}{|c|c|c|c|c|c|c|}
\hline $\begin{array}{c}\text { Weiss et al., } 2007 \text { (27) } \\
n=112\end{array}$ & 27 & $11(10)$ & $13(12)$ & 24 & NS & 4 \\
\hline $\begin{array}{c}\text { Chung et al., } 2007 \text { (28) } \\
n=340\end{array}$ & 90 & $50(15)$ & $31(9)$ & 24 & NS & 7 \\
\hline $\begin{array}{c}\text { Gogna et al., } 2006 \text { (20) } \\
n=113\end{array}$ & 23 & $11(14)$ & $18(16)$ & 26 & NS & 9 \\
\hline $\begin{array}{l}\text { Hussain et al., } 2004 \text { (29) } \\
n=41\end{array}$ & 51 & $2(5)$ & $2(5)$ & 10 & NS & 17 \\
\hline $\begin{array}{c}\text { Rödel et al., } 2002 \text { (30) } \\
\text { (Erlangen) } \\
n=415\end{array}$ & 60 & $32(8)$ & $41(10)$ & 26 & $10(2)$ & NS \\
\hline $\begin{array}{c}\text { Shipley et al., } 1998 \text { (13) } \\
\text { n=62 (arm 2) }\end{array}$ & 60 & NS & NS & NS & $9(14)$ & 39 \\
\hline $\begin{array}{l}\text { Housset et al., } 1993 \text { (21) } \\
\mathrm{n}=54\end{array}$ & 27 & $2(5)$ & $2(5)$ & 10 & NS & 15 \\
\hline
\end{tabular}

MIBC: muscle-invasive bladder cancer. NMIBC: non-muscle-invasive bladder cancer. CR: complete response. NS: non stated. FCT: Fluorouracil plus cisplatin and radiation twice a day. GD: Gemcitabine and once daily radiation. P1: protocol 1, neoadjuvant methotrexate, cisplatin and vinblastine (MCV). P2: protocol 2, cisplatin and concurrent radiotherapy. WP: whole pelvis concurrent chemoradiation (CCRT). BO: bladder-only CCRT. 
Table 3. Toxicity Rates Associated with TMT for MIBC

\begin{tabular}{|c|c|c|c|c|c|c|}
\hline Author & $\begin{array}{c}\text { Follow up } \\
\quad(\mathrm{mo})\end{array}$ & $\begin{array}{c}\text { Completion } \\
\text { rates } \\
(\%)\end{array}$ & $\begin{array}{c}\text { GI toxicity Grade } 3-4 \\
\text { immediate/late } \\
\text { n (\%) }\end{array}$ & $\begin{array}{c}\text { GU toxicity grade 3-4 } \\
\text { immediate / late } \\
\text { n (\%) }\end{array}$ & $\begin{array}{c}\text { Late toxicity } \\
\text { grade } 3-4 \text { in } \\
\text { global } \\
\text { n }(\%)\end{array}$ & $\begin{array}{c}\text { Salvage cystectomy rate } \\
\text { due to toxicity } \\
(\%)\end{array}$ \\
\hline $\begin{array}{c}\text { Coen et al., } \\
2019(14) \\
n=66\end{array}$ & 60 & $\begin{array}{l}\text { FCT: } 93 \\
\text { GD: } 92\end{array}$ & $\begin{array}{c}\text { FCT: } 2(6) \\
\text { GD: } 3(9)\end{array}$ & $\begin{array}{l}\text { FCT: } 2(6) \\
\text { GD: } 2(6)\end{array}$ & $\begin{array}{l}\text { FCT: } 8(25) \\
\text { GD: } 5(16)\end{array}$ & NS \\
\hline $\begin{array}{c}\text { Büchser et al., } \\
2018(22) \\
n=90\end{array}$ & 94 & NS & $\begin{array}{l}\text { NS / } 6(7) \\
\text { Grade } \geq 2\end{array}$ & $\begin{array}{l}\text { NS / } 22(24) \\
\text { Grade } \geq 2\end{array}$ & NS & 1 \\
\hline $\begin{array}{c}\text { James et al., } 2012 \\
(12) \\
\mathrm{n}=182 \\
\end{array}$ & 70 & 80.2 & 17 (9.6) / NS & 38 (21.3) / NS & $10(8.3)$ & NS \\
\hline $\begin{array}{c}\text { Zapatero et al., } \\
2012(16) \\
n=80\end{array}$ & 72 & NS & $\begin{array}{l}\text { NS/ } 5(16) \\
\text { Grade } \geq 2\end{array}$ & $\begin{array}{l}\text { NS/ } 18(22) \\
\text { Grade } \geq 2\end{array}$ & NS & NS \\
\hline $\begin{array}{c}\text { Choudhury et al., } \\
2011 \text { (18) } \\
n=50\end{array}$ & 36 & 92 & NS & NS & NS & 2 \\
\hline $\begin{array}{c}\text { Kaufman et al., } \\
2009(19) \\
n=80\end{array}$ & 49 & 70 & $\begin{array}{c}\text { Induction } 12(15), \\
\text { consolitadion } 4(5 / 0)\end{array}$ & $\begin{array}{c}\text { Induction } 3(4), \\
\text { consolitation 2(2)/ 3(4) }\end{array}$ & NS & NS \\
\hline $\begin{array}{c}\text { Perdonà et al., } \\
2008(26) \\
\text { n=121 }\end{array}$ & 66 & 95 & $15(12.4) / 2(2)$ & $14(11.5) / 4(3)$ & NS & 0.8 \\
\hline
\end{tabular}




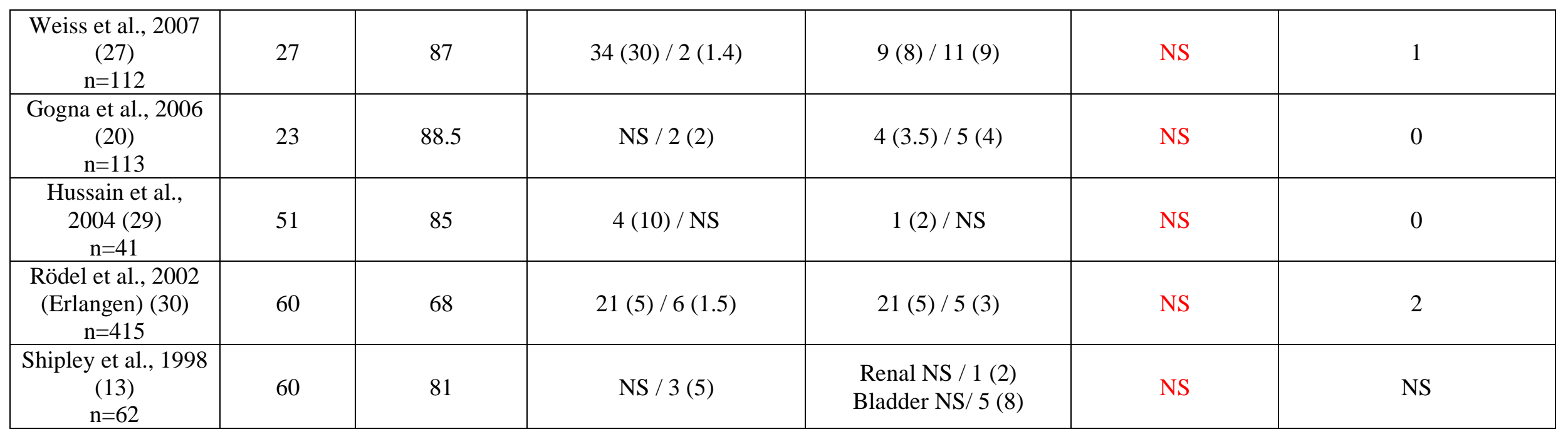

GI: gastrointestinal. GU: genitourinary. NS: non stated. FCT: Fluorouracil plus cisplatin and radiation twice a day. GD: Gemcitabine and once daily radiation. WP: whole pelvis concurrent chemoradiation (CCRT). BO: bladder-only CCRT. 
Table 4. Ongoing Clinical Trials including Immune Checkpoint Inhibitors

\begin{tabular}{|c|c|c|c|c|c|c|}
\hline Drug & $\mathbf{n}$ & $\begin{array}{l}\text { Inclusion } \\
\text { Criteria }\end{array}$ & Combination & $\begin{array}{l}\text { Primary } \\
\text { Endpoint }\end{array}$ & Secondary Endpoint & $\begin{array}{l}\text { Expected } \\
\text { Accrural }\end{array}$ \\
\hline NCT02662062 & 30 & $\begin{array}{l}\text { cT2-4a TCC, } \\
\text { Nx or N0 }\end{array}$ & $\begin{array}{l}\text { Pembrolizumab + } \\
\text { Cisplatin + RT }\end{array}$ & $\begin{array}{l}\% \text { pts w/ grade } 3 \\
\text { and } 4\end{array}$ & $\begin{array}{l}\text { Efficacy of adding } \\
\text { pembrolizumab to SOC } \\
\text { TMT; \% pts w/ M+; \% } \\
\text { pts w/ SC }\end{array}$ & 2024 \\
\hline NCT02621151 & 54 & $\begin{array}{l}\text { cT2-T4a TCC } \\
\text { N0 M0 TCC }\end{array}$ & $\begin{array}{l}\text { Pembrolizumab + } \\
\text { Gemcitabine + RT }\end{array}$ & $\begin{array}{l}\text { Bladder-intact } \\
\text { DFS at } 2 y\end{array}$ & $\begin{array}{l}\text { Safety, CR rates, OS, } \\
\text { MFS }\end{array}$ & 2026 \\
\hline $\begin{array}{l}\text { NCT } 03702179 \\
\text { (IMMUNOPRESERVE) }\end{array}$ & 32 & cT2-T4a TCC & $\begin{array}{l}\text { Durvalumab + } \\
\text { Tremelimumab + RT }\end{array}$ & $\begin{array}{l}\% \text { pts } \mathrm{w} / \text { path } \\
\text { response }\end{array}$ & $\begin{array}{l}\% \text { pts w/ bladder } \\
\text { preserved at } 24 \mathrm{mo} ; \% \\
\text { SC, DFS, OS, } \\
\text { Treatment related } \\
\text { events }\end{array}$ & 2022 \\
\hline \multicolumn{7}{|l|}{ Nivolumab } \\
\hline NCT03421652 (NUTRA) & 34 & cT2-4b N0-1 & Nivolumab + RT & PFS & $\begin{array}{l}\text { Adverse events; } \\
\text { Response rate, MFS, } \\
\text { OS }\end{array}$ & 2020 \\
\hline NCT03171025 (NEXT) & 28 & $\begin{array}{l}\text { cT2-T4a N0 } \\
\text { or N+ M0; T1 }\end{array}$ & $\begin{array}{l}\text { Adjuvant Nivolumab } \\
\text { after TMT }\end{array}$ & $\begin{array}{l}\text { 2y-Failure Free Sx } \\
\text { (locaregional }\end{array}$ & $\begin{array}{l}\text { Failure Free Survival at } \\
2 y\end{array}$ & 2024 \\
\hline
\end{tabular}




\begin{tabular}{|c|c|c|c|c|c|c|}
\hline & & w/ N+ & & $\begin{array}{l}\text { recurrence and } \\
\text { distand) }\end{array}$ & & \\
\hline \multicolumn{7}{|l|}{ Avelumab } \\
\hline NCT03617913 & 27 & $\begin{array}{l}\text { cT2-4a N0M0 } \\
\text { TCC }\end{array}$ & $\begin{array}{l}\text { Avelumab + } \\
\text { 5FU/MMC/Cisplatin }+ \\
\text { RT }\end{array}$ & CR & $\begin{array}{l}\text { Adverse events; } \\
\text { EORTC-QLQ-30/BLM } \\
\text { 30; PFS, RFS }\end{array}$ & 2025 \\
\hline
\end{tabular}

Abbreviations:

RT: Radiotherapy; TMT: Trimodal therapy; TCC: Transitional cell carcinoma; DFS: Disease Free Survival; DLT: Dose Limiting Toxicity; OS: Overall Survival; MFS: Metastasis Free Survival; Progression Free Survival. 